\title{
A Projection for the Turkish Economy in 2023 with a Bayesian Approach
}

\author{
Dr. Mesut Murat Arslan \\ Yildirim Beyazit University \\ Dr. Fatma Ozgu Serttas \\ Yildirim Beyazit University \\ Dr. Recai Aydin \\ Turkish Police Academy \& International University of Sarajevo
}

\begin{abstract}
Turkish economy has almost experienced a continuous growth process since the first quarter of the year 2002, except for the year 2009 in which the impact of global financial crisis was felt. As a result of this growth period, Turkey has become the 17th largest economy in the world and has set big targets as to join one of the largest 10 economies in the world. In this study, we investigate whether Turkey would be able to meet its 2023 targets or not if the trends and dynamics that have been experienced during the last decade continue. Specifically, we will examine if Turkey's exports will reach 500 billion US dollars, Turkey's GDP will reach 2 trillion US dollars, and Turkey's GDP per capita will reach 25 thousand US dollars. Furthermore, the path that Turkey's macroeconomic indicators should follow in coming years and the different applicable scenarios in order to reach these 2023 economic targets will be studied. The results of this study show that those 2023 targets will not be met. So if Turkey is serious and insistent on these targets, this study may be a warning to policymakers to take the necessary measures when there is still enough time and oppurtunity.
\end{abstract}

Keywords: Turkish Economy, DSGE-VAR, SOE, Bayesian Methods. Jel Classification: C11,C13,C68

\section{INTRODUCTION}

The Turkish economy has almost experienced a continuous growth process since the first quarter of the year 2002, except for the year 2009 in which the impact of global financial crisis was felt. As a result of this growth period, Turkey has become the $17^{\text {th }}$ or $18^{\text {th }}$ largest economy in the world. ${ }^{1}$ Following this remarkable economic performance, Turkey has set some big targets for 2023 as: $i$. being one of the largest 10 economies in the world; $i$. reaching GDP of 2 trillion US dollars; iii. having per capita GDP of 25 thousand US dollars; iv. Having export of 500 billion US dollars.

\footnotetext{
${ }^{1}$ According to the IMF, World Bank and UN ranking based on nominal GDPs in 2014 and 2015, Turkey is the $18^{\text {th }}$ country in the list. However, according to GDP calculated by purchasing power parity (PPP), Turkey is $17^{\text {th }}$ country in the world GDP ranking lists.
} 
Thus, in this study, we investigate whether Turkey would be able to meet its 2023 targets or not if the trends and dynamics that have been experienced during the last decade continue. Of course, the first target of being among the 10 largest economies and Turkey's ranking in the world economy in 2023 are closely related to the performance of other similar. So in order to see whether this target will be met, the projections which will be made for the Turkish economy will also be applied to some of those economies which are below and above the Turkey's ranking. Because in this study, we also propose a new methodology and approach for projections, we will just focus on projections on Turkey, and postpone the projections of other countries and comparisons to some other study. Therefore, in this study, we will just specifically look at the feasibility of GDP, per capita GDP, and exports targets of Turkey in 2023.

In this study, the Turkish economy will be modeled and investigated through a Small Open Economy (SOE) theoretical model based on Gali and Monacelli (2005). This model is a version of Dynamic Stochastic General Equilibrium (DSGE) model. The projections in this study will be made through Bayesian estimations of a DSGE-VAR (or DSGE-VAR $(\lambda)$ ) model that is obtained from the combination of a structural DSGE model with a Vector Autoregression (VAR) model. Therefore, theDSGE-VAR $(\lambda)$ model establishes a balance between the statistical representation (VAR) and the economic requirement (DSGE). So here, the DSGE-VAR or DSGE-VAR $(\lambda)$ model that will be estimated by using Bayesian methods represents a combination ofour SOE model with a VAR model. ${ }^{2}$ DSGE models are generally used in the analyses of short term macroeconomic policy within the New Keynesian framework. The long term projections are made generally by the VAR models. In this study, these two approaches will be combined and projections will be made by using a VAR model starting from a structural DSGE model. Because in literature, there are no long term projections and estimations made within such a framework at least to our knowledge, this study will contribute the literature.

In addition to the theoretical and methodological contributions, this study could provide information and guidance to policymakers in their way of reaching the targets. So, if they are serious on those targets, and such studies arrive at a conclusion that these targets are not attainable, then the attention of policymakers and the public can be captured when there is still enough time to take the necessary measures. Another contribution could be introducing of using Bayesian methods and techniques in Turkey in the context of long term projections, where there are not enough studies using this state-of-art estimation method.

${ }^{2}$ The hyperparameter $\lambda$ is interpreted as the weight placed on both the VAR and the DSGE parts of the DSGE-VAR $(\lambda) . \lambda \rightarrow \infty$ : DSGE-VAR $(\lambda) \rightarrow$ DSGE; $\lambda \rightarrow 0$ : $\operatorname{DSGE}-\operatorname{VAR}(\lambda) \rightarrow$ VAR. 


\section{THE LITERATURE}

\subsection{DSGE Models}

We will use a small open economy (SOE) model which is a variant of the dynamic stochastic general equilibrium (DSGE) model in this study. This is an open economy version of the standard model used in New Keynesian framework (see Woodford, 2003) developed first by Gali and Monacelli's (2005). Its simplification by Lubik and Schorfheide (2007) has become standard and vastly used in the literature. DSGE models are microfounded optimizationbased models that have become very popular in macroeconomics over the past 25-30 years. DSGE models are the models with a high degree of theoretical coherence and derived from the first principle by explicitly modeling the household and firm behavior as well as the monetary authority's reaction function. In these models, decision rules of economic agents are derived from assumptions about agents' preferences and production technologies and some fundamental principles such as intertemporal optimization, rational expectations, and competitive equilibrium. Thus, they are robust against the well-known Lucas (1976) critique, and a good model for policy analysis. However in such models, the functional forms and parameters of equations that describe the behavior of economic agents are tightly restricted by optimality and equilibrium conditions. But, likelihood functions for such empirical models with a strong degree of theoretical coherence tend to be more restrictive than likelihood functions associated with atheoretical models. However, a challenge arises if the data favor the atheoretical model. Since the atheoretical model generates more accurate forecasts, but a theoretically coherent model is required for the analysis of a particular economic policy.

In literature DSGE models could be estimated by different methods. Clarida and Gali and Gertler (2000) used GMM. Orphanides (2001) and Ball and Tchaidze (2002) used OLS methods but to avoid endogeneity bias they made implausible identification assumptions. Fuhrer and Moore (1995), Leeper and Sims (1994), Kim (2000) used full-information maximum likelihood estimation (MLE) method. However, one problem in the estimation of DSGE models by MLE is absurd parameter estimates, that is, estimates of structural parameters by MLE are often at odds with additional information or observations. Because of such problems DSGE models have been estimated by Bayesian methods recently. Likelihood-based Bayesian estimations of DSGE models have started with the studies of Landon-Lane (1998), DeJong et all. (2000), Schorfheide (2000) and Otrok (2001). An analysis and estimation of a DSGE model by Bayesian methods in a closed economy framework was performed by An and Schorfheide 
(2007). In open-economy literature, Lubik and Schorfheide (2007) used Bayesian estimation methods in a SOE framework to see the effects of exchange rates movement on the monetary policies of some central banks (to investigate the hypothesis whether central banks do respond to exchange rates). Lubik and Schorfheide (2006), Rabanal and Tuesta (2006), Walque and Wouters (2004) used Bayesian methods in the estimations of multi-country DSGE models.

\subsection{VAR Models}

While DSGE models provide a complete multivariate stochastic process representation for the data, simple models impose very strong restrictions on actual time series and are in many cases rejected against less restrictive specifications such as Vector Autoregressions (VAR). A natural alternative to DSGE models in dynamic macroeconomics is a VAR model, because linearized DSGE models, at least approximately, can be interpreted as restrictions on a VAR representation. Thus, instead of estimating a structural model of the economy, we can directly estimate a model by using observable variables and data without having any restrictions, as in a VAR model. VARs are linear time-series models, designed to capture the joint dynamics of multiple time series.

Therefore, VAR models are usually used in long-term estimations and making future projections. Sims (1980) proposed VARs to replace large-scale macroeconometric models (inherited from the 1960s), which impose incredible restrictions. Since then, VARs have been used for macroeconomic forecasting and policy analysis to investigate the sources of business-cycle fluctuations and to provide a benchmark against which modern dynamic macroeconomic theories can be evaluated. The equilibrium law of motion of many dynamic stochastic equilibrium models can be well approximated by a VAR. There are some problems in the estimations and forecasting with VAR models. Since the VAR parameter space is generally much larger than the DSGE model parameter space, the specification of a prior distribution for the VAR parameter becomes very important and requires careful attention. A VAR with a prior that is very diffuse is likely to be rejected even against a misspecified 2016/1 DSGE model (An and Schorfheide (2007)). ${ }^{3}$

\footnotetext{
${ }^{3}$ In a more general context this phenomenon is often called Lindley's paradox.
} 


\section{THE MODEL AND ESTIMATION METHOD}

\subsection{DSGE-VAR and Bayesian Approach}

In empirical studies the guidance of theory is crucial. However, since theoretical models have been getting more complicated, complex and very specific in macroeconomics, this guidance in a formal statistical framework has become more difficult. Bayesian estimation methods provide a statistical framework to overcome such difficulties and take formally uncertainties in model parameters into account. In Bayesian inference, prior distributions for parameters are updated by sample information contained in the likelihood functions to form posterior distributions. In a Bayesian framework, prior distributions are important. The prior can enable to use information that is not contained in the estimation sample. Thus, to the extent that the prior is based on nonsample information, it provides the ideal framework for combining different sources of information and thereby sharpening inference, and obtaining more correct and consistent estimations in macroeconometric analysis. Then, posterior distributions can beobtained to measure parameters' uncertainty, and used in making political analysis, estimations, and future forecasting.

Thus, with a DSGE-VAR model in Bayesian framework, since the likelihood function is reweighted by a prior density that can bring the information to the model that is not contained in the estimation sample, more reasonable and consistent estimations can be obtained. In a DSGE-VAR model, probability distributions for parameters are determined by a DSGE model that models the economy theoretically. These distributions are used as prior distribution in VAR to obtain estimations and projections that are consistent with the assumed economic model. Then, the posterior distribution of DSGE-VAR model is derived from combining a VAR likelihood function with the DSGE priors. The DSGE priors here are used instead of the Minnesota-styled priors that are usually used in the Bayesian VAR (BVAR).

DSGE-VAR model obtained by combining DSGE models with Bayesian VARs first proposed by Ingram and Whiteman (1994), and further developed by Del Negro and Schorfheide (2004) to improve forecasting and monetary policy analysis with VARs. Then the framework has been extended to a model evaluation tool in Del Negro et al. (2007). The main point in these studies is to determine the moments of the prior distribution of the VAR parameters by using a DSGE model. DSGE-VAR approach was designed to improve forecasting and monetary policy analysis with VARs, and some studies find that this model can compete in forecasting with BVARs based on the Minnesota prior (Del Negro and Schorfheide $(2006,2009))$. Since unlike the BVAR, where the 
so-called Minnesota priors are used to tilt the estimates toward random walks in the parameter space, the DSGE-VAR model uses the artificial data generated from the DSGE to tilt the estimates toward the region of the parameter space. This would produce better and more consistent estimation results when theoretically strong DSGE models are used.

\subsection{The Small Open Economy (SOE) Model}

A SOE-DSGE model includes an open economy IS curve that represents the production side of the economy, a new Keynesian Phillips curve that represents inflation dynamics, a real exchange rate equation, and a monetary policy rule. Thus, the SOE model that will be used in this study can be described by the following equations.

The consumption Euler equation showing the supply side of the economy can be rewritten as an open economy IS-curve:

$$
\begin{aligned}
& \mathrm{y}_{\mathrm{t}}=\mathrm{E}_{\mathrm{t}} \mathrm{y}_{\mathrm{t}+1}-[\tau+\alpha(2-\alpha)(1-\tau)]\left(\mathrm{R}_{\mathrm{t}}-\mathrm{E}_{\mathrm{t}} \pi_{\mathrm{t}+1}\right)-\rho_{\mathrm{z}} \mathrm{z}_{\mathrm{t}} \\
& -\alpha[\tau+\alpha(2-\alpha)(1-\tau)] \mathrm{E}_{\mathrm{t}} \Delta \mathrm{q}_{\mathrm{t}+1}+\alpha(2-\alpha) \frac{1-\tau}{\tau} \mathrm{E}_{\mathrm{t}} \Delta \mathrm{y}_{\mathrm{t}+1}^{*}
\end{aligned}
$$

where $0<\alpha<1$ is the import share, $\tau$ is the intertemporal substitution elasticity, $y$ is aggregate output, and $\pi$ is the CPI inflation rate. The terms of trade, $\mathrm{q}$ is defined as the relative price of exports in terms of imports. $y^{*}$ is exogenous world output, and $\mathrm{z}$ is the growth rate of an underlying non-stationary world technology process A. 4

Optimal price setting of domestic firms leads to the open economy Phillips curve:

$$
\pi_{\mathrm{t}}=\beta \mathrm{E}_{\mathrm{t}} \pi_{\mathrm{t}+1}+\alpha \beta \mathrm{E}_{\mathrm{t}} \Delta \mathrm{q}_{\mathrm{t}+1}-\alpha \Delta \mathrm{q}_{\mathrm{t}}+\frac{\kappa}{\tau+\alpha(2-\alpha)(1-\tau)}\left(\mathrm{y}_{\mathrm{t}}-\overline{\mathrm{y}}_{\mathrm{t}}\right)
$$

where $\bar{y}$ is potential output in the absence of nominal rigidities. The slope coefficient $\kappa$ is a function of underlying structural parameters, such as labor supply and demand elasticities and parameters capturing the degree of price stickiness.

The nominal exchange rate $\mathrm{e}$ is included into the model through

the definition of the CPI by assuming that relative PPP holds:

$$
\pi_{\mathrm{t}}=\Delta \mathrm{e}_{\mathrm{t}}+(1-\alpha) \Delta \mathrm{q}_{\mathrm{t}}+\pi_{\mathrm{t}}^{*}
$$

where $\pi^{*}$ is an unobserved world inflation shock, and may also be interpreted as the misspecification, or deviations from PPP.

Monetary policy is described by a Taylor-type interest rate rule, where the central bank adjusts its instrument in response to movements in CPI inflation, output, and nominal exchange rate:

$$
\mathrm{R}_{\mathrm{t}}=\rho_{\mathrm{R}} \mathrm{R}_{\mathrm{t}-1}+\left(1-\rho_{\mathrm{R}}\right)\left[\psi_{1} \pi_{\mathrm{t}}+\psi_{2} \mathrm{y}_{\mathrm{t}}+\psi_{3} \Delta \mathrm{e}_{\mathrm{t}}\right]+\varepsilon_{\mathrm{t}}^{\mathrm{R}}
$$

\footnotetext{
${ }^{4}$ In order to guarantee stationary of the model, all real variables are therefore expressed in terms of percentage deviations from $A$.
} 
Where $\psi$ s represent monetary policy coefficients, and is a smoothing term that accounts the persistence in nominal interest rates.

The terms of trade can be determined endogenously as the relative price that clears international goods markets. However, estimation of the fully structural model turned out to be problematic as explained in Lubik and Schorfheide (2007). For most specifications, numerical optimization routine had difficulties finding the maximum of the posterior density. Whenever optimization did converge, implausible parameter estimates and low likelihood values are obtained. The apparent reason is that endogenous equation would imply a tight link between the terms of trade and output growth that the estimation procedure attempts to match. This creates a conflict with output and inflation dynamics as governed by the IS-equation and the Phillips-curve, which can at best only be resolved at the cost of implausible estimates. To overcome such difficulties, a law of motion for the growth rate of the terms of trade can be added to the system of equations given above:

$$
\Delta \mathrm{q}_{\mathrm{t}}=\rho_{\mathrm{q}} \Delta \mathrm{q}_{\mathrm{t}-1}+\varepsilon_{\mathrm{q}, \mathrm{t}}
$$

These five equations given above form a linear rational expectations model. Here it will be assumed that the variables representing the world and evolve according to univariate $\mathrm{AR}(1)$ processes with autoregressive coefficients and, respectively. The innovations of the $\mathrm{AR}(1)$ processes are denoted by and. This rational expectations model can be solved by different methods. Linear approximation methods are very popular.Since a loglinearized DSGE model with rational expectations can be put in a state-space form, where the observed variables are linked to the model variables through the measurement equation. At the same time, the state equation provides the reduced form of the DSGE model, mapping current variables to their lags and the i.i.d. shocks. The reduced form is obtained by solving for the expectation terms in the structural form of the model using a suitable numerical technique. The most common methods are Anderson and Moore's (1985) AiM algorithm, Klein (2000), and Sims (2002).5 If a unique convergent solution is available, the Kalman filter can be applied to compute the value of the log-likelihood function.

\subsection{Estimation in Bayesian Framework}

After solving the DSGE model, a parameter vector that needs to be estimated is formed. This vector is composed of unknown model parameters, policy rule parameters, and parameters for the shocks.

\footnotetext{
${ }^{5}$ See also Blanchard and Kahn (1980), Anderson (2008, 2010), Christiano (2002), King and Watson (1998).
} 
Under the assumption that all the structural shocks are normally distributed and uncorrelated with each other at all leads and lags we can obtain a joint probability distributionfor the endogenous model variables. The solution of the rational expectations system takes the form

$$
s_{t}=\Phi\left(s_{t-1}, \epsilon_{t} ; \theta\right)
$$

The variables in the rational expectations system are represented by the vector $s_{t}$. From an econometric perspective, $s_{t}$ can be viewed as a (partially latent) state vector in a non-linear state space model and the above equation is the state transition equation. Here, is the vector of innovations and the structural parameters are collected in the vector $\theta$ that are the parameters to estimate in the model. The model is completed by defining a set of measurement equations that relate the elements of st to a vector of observations, Y.

The unknown parameters will be estimated by Bayesian techniques. A Bayesian approach is in principle easy. Parameters are given values through their posterior distribution, which is linked to prior information and the observed data through Bayes theorem. From Bayes theorem we know that the posterior distribution of $\theta$, denoted by $\mathrm{p}(\theta \mid \mathrm{Y})$, is given as

$$
p(\theta \mid Y)=\frac{p(Y \mid \theta) p(\theta)}{p(Y)}
$$

where $\mathrm{p}(\theta)$ is the prior density, $\mathrm{p}(\mathrm{Y} \mid \theta)$ is the density function for a random data matrix $\mathrm{Y}$ conditional on $\theta$, and $\mathrm{p}(\mathrm{Y})$ is the marginal data density that is defined as

$$
p(Y)=\int p(Y \mid \theta) p(\theta) d \theta=\int \mathcal{L}(\theta \mid Y) p(\theta) d \theta
$$

As can be seen from the above equation, the density function $p(Y \mid \theta)$ can be represented by the likelihood function associated with the DSGE model and Yis the vector of observables. ${ }^{6}$ In a Bayesian framework, the likelihood function is reweighted by a prior density. If the likelihood function peaks at a value that is at odds with the information that has been used to construct the prior distribution, then the marginal data density of the DSGE model, will be low compared to, say, a VAR.

\footnotetext{
${ }^{6}$ In this marginal density of the datawith $\Theta$ being the support of $\theta$. Since $p(\mathrm{Y})$ is a constant when $\mathrm{Y}$ has been realized we know from the Bayes theorem that the posterior density of $\theta$ is proportional to the product $p(\mathrm{Y} \mid \theta) p(\theta)$. Hence, if we can characterize the distribution of this product we would know the posterior distribution of $\theta$. For complex models like those belonging to the DSGE family this characterization is usually not possible. Methods based on Markov Chain Monte Carlo (MCMC) theory can instead be applied to generate draws from the posterior.
} 
If the pure Bayesian approach is used, a prior distribution for each parameter is assigned, and the data are used to update these priors through the likelihood function of the DSGE model.Then, by using Bayes theorem the posterior distributions can be obtained. In a Bayesian framework, this likelihood function can be used to transform a prior distribution for the structural parameters of the DSGE model into a posterior distribution. This posterior is the basis for inference and decision making.

However, in the DSGE-VAR estimation method, the DSGE model is used to determine the moments of the prior distribution of the VAR parameters using a normal/inverted Wishart distribution. Thus, possible distributions of parameters are determined by using a DSGE model that theoretically represents the economy. These distributions are used as priors in VAR estimation, so estimation and forecasting results that are consistent with the assumed economy could be obtained. That is, dummy observations priors are obtained by the DSGE model, and then these DSGE priors are used to weigh the VAR likelihood function in order to derive the posterior distribution. These posterior distributions are used for posterior sampling or posterior mode estimation to obtain estimation or forecasting results. The DSGE priors here are used instead of the Minnesota-styled priors that are usually used in the BVAR. It is found that this model can compete in forecasting exercises with BVARs based on the Minnesota prior.

The DSGE- $\operatorname{VAR}(\lambda)$ shows an equilibrium between economic requirement represented by a theoretical model (DSGE) and statistical representation in an empirical framework (VAR) depending on the optimum value of $\lambda$. Since the empirical performance of the DSGE-VAR $(\lambda)$ procedure crucially depends on the weight placed on each part, a data-driven procedure to determine optimum $\lambda$ will be used (An and Schorfheide (2007)). A natural criterion for the choice of $\lambda$ in a Bayesian framework is the marginal data density

$$
p_{\lambda}(Y)=\int p_{\lambda}(Y \mid \theta) p(\theta) d \theta
$$

For computational reasons we restrict the hyperparameter to a finite grid of $\lambda$ s. If one assigns equal prior probability to each grid point then the normalized $p_{\lambda}(Y)$ 's can be interpreted as posterior probabilities for $\lambda$. Then the optimum value for $\lambda$ can be obtained from:

$$
\hat{\lambda}=\underset{\lambda \in \Lambda}{\operatorname{argmax}} p_{\lambda}(Y)
$$




\section{THE ESTIMATION RESULTS}

In this study, seasonally adjusted quarterly data set for Turkey will be used. The data set includes nominal GDP, inflation rates, short-term interest rates, nominal exchange rates, and terms of trades. In estimations and forecasting, growth rates of output will be used; inflation will be taken as the change in CPI; exchange rates will be either trade-weighted nominal exchange rate or simply dollar exchange rates. Since the changes in exchange rates and terms of trades will be used in estimations, log differences of those variables will be taken.

Two data sets for Turkey are used in forecasting, one covers the period 1998:2-2015:4, and the other period 2002:1-2015:4. Although the first set has more observations, it also includes the effects of big crisis in Turkey in 2001. However, the second set covers observations after the crisis, so it represents a period in which Turkey is more stable. Thus, it might be thought that a projection using the second set may reflect the current dynamics of Turkey more and also carry these into the future in a better way.

The model is estimated through Bayesian estimation methods described above and quarterly projection results are obtained. Table 1 shows the annual results of projection calculated from quarterly results when $1998-2015$ data set is used. Also, it tabulates three confidence bands of 50\%, 70\% and $90 \%$ calculated for this projection. Such as the values for $90 \%$ confidence band indicates that projection results would be in this interval with $90 \%$ probability. Figure 1 shows quarterly projection results graphically that are used to obtain annual results given in Table 1. According to these results, nominal GDP of Turkey in 2023 is projected to be 3.8 trillion TL. Also it can be expected that GDP in 2023 would be between 3.59 trillion and 3.99 trillion liras with $90 \%$ probability. The projection results obtained when 2002-2015 results are used are given in Table 2 and Figure 2. They indicates that the higher projection results are obtained with the data set that excludes the 2001 crisis, and 2023 GDP is projected to be 4.72 trillion TL. Similar projections are also implemented in US dollars and the results are given in Table 3, 2016/1 Turkey's GDPs in 2023 is found to be 942.4 billion dollars and 947.2 billion dollars for the two data sets. These findings show that Turkey's GDP target of reaching 2 trillion dollars in 2023 seems to be far from achieving.

Per capita GDP projections are given in Table 5 and Table 6. According to these results GDP per capita in 2023 is projected to be around 11.200 dollars, and 90\% confidence band results shows that this figure could be realized as highest as 12.000 dollars with probability of $90 \%$. Therefore, these findings show that it is extremely difficult for Turkey to reach the per capita target level of 25.000 dollars in 2023. 
A Projection for the Turkish Economy in 2023 with a Bayesian Approach

Table 1: Nominal GDP Projections with 1998-2015 Data - TL

\begin{tabular}{|l|l|l|l|l|l|l|l|}
\hline \multirow{2}{*}{ Year } & \multirow{2}{*}{$\begin{array}{l}\text { Nom.GDP } \\
(1000 \mathrm{TL})\end{array}$} & \multicolumn{5}{|c|}{ Confidence Interval } \\
\hline $\begin{array}{l}2015 \\
2016\end{array}$ & $\begin{array}{l}1952724009 \\
2193749416\end{array}$ & 2150714971 & 2232520925 & 2134096574 & 2253937948 & 2104694703 & 2287879265 \\
\hline 2017 & 2406717216 & 2362485652 & 2456648353 & 2331234081 & 2477383867 & 2294364246 & 2515110036 \\
\hline 2018 & 2625544162 & 2575736488 & 2680796985 & 2544951019 & 2709645749 & 2491961424 & 2766325150 \\
\hline 2019 & 2847140174 & 2783904122 & 2909063081 & 2759677984 & 2941297862 & 2705912849 & 2986203550 \\
\hline 2020 & 3074239791 & 3009787960 & 3143449030 & 2970692811 & 3174796445 & 2909766651 & 3238328122 \\
\hline 2021 & 3307628174 & 3242805705 & 3363672744 & 3207626674 & 3401163898 & 3151116033 & 3454044063 \\
\hline 2022 & 3547673244 & 3473454840 & 3614624077 & 3435794156 & 3666190783 & 3364553222 & 3723388383 \\
\hline 2023 & 3795193990 & 3712127398 & 3870907018 & 3673746596 & 3910672754 & 3589206313 & 3995732916 \\
\hline
\end{tabular}

Figure 1: Nominal GDP Projections with 1998-2015 Data

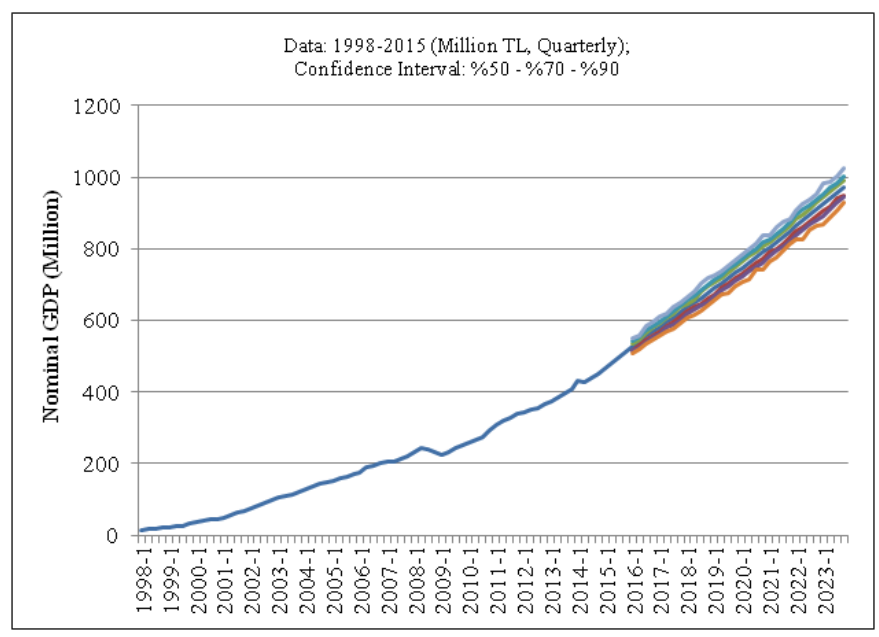

Table 2: Nominal GDP Projections with 2002-2015 Data - TL

\begin{tabular}{|c|c|c|c|c|c|c|c|}
\hline Year & Nom.GDP & \multicolumn{6}{|c|}{ Confidence Interval } \\
\hline 2015 & 1952724009 & \multicolumn{2}{|c|}{$50 \%$} & \multicolumn{2}{|c|}{$70 \%$} & \multicolumn{2}{|c|}{$90 \%$} \\
\hline 2016 & 2262066340 & 2221037944 & 2304509157 & 2199508443 & 2325397912 & 2163984989 & 2371761603 \\
\hline 2017 & 2598143283 & 2550010624 & 2648562648 & 2517288533 & 2678684905 & 2466901117 & 2723968058 \\
\hline 2018 & 2944276252 & 2890178910 & 2997265375 & 2851333622 & 3034014474 & 2806117803 & 3075747459 \\
\hline 2019 & 3288115690 & 3213169550 & 3360336406 & 3172140651 & 3397247470 & 3110472783 & 3471206420 \\
\hline 2020 & 3631337085 & 3545853333 & 3716175017 & 3508599029 & 3753194814 & 3440753719 & 3826279266 \\
\hline 2021 & 3980038870 & 3894526203 & 4067389578 & 3855056734 & 4110047341 & 3783519263 & 4178206433 \\
\hline 2022 & 4339937130 & 4244517251 & 4439772203 & 4183699624 & 4489845853 & 4118373300 & 4560201075 \\
\hline 2023 & 4716567615 & 4624202565 & 4809816086 & 4582123040 & 4869340126 & 4475340483 & 4928979127 \\
\hline
\end{tabular}


M. M. Arslan et al.

Figure 2: Nominal GDP Projections with 2002-2015 Data

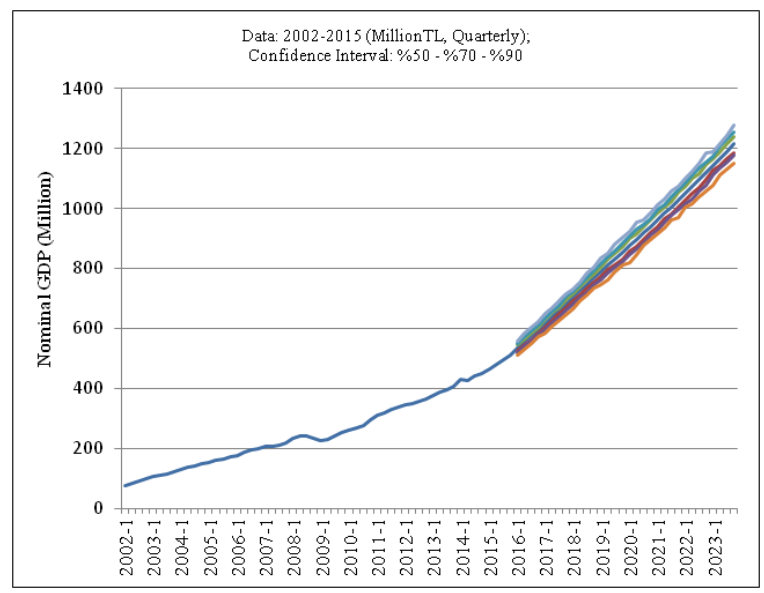

Table 3: GDP Projection with 1998-2015 Data - USD

\begin{tabular}{|l|l|l|l|l|l|l|l|}
\hline \multirow{2}{*}{ Year } & \multirow{2}{*}{$\begin{array}{l}\text { Nom.GDP } \\
(1000 \text { USD })\end{array}$} & \multicolumn{5}{|c|}{ Confidence Interval } \\
\hline $\begin{array}{l}2015 \\
2016\end{array}$ & $\begin{array}{l}721051070 \\
708891564\end{array}$ & 678250146 & 735392054 & 666045267 & 752679076 & 640813019 & 779743837 \\
\cline { 3 - 8 } & \multicolumn{2}{|c|}{$50 \%$} & \multicolumn{2}{|c|}{$70 \%$} & \multicolumn{2}{c|}{$90 \%$} \\
\hline 2017 & 728773540 & 691806891 & 769305255 & 669084167 & 788727180 & 645364937 & 823308215 \\
\hline 2019 & 757975618 & 725538167 & 793373864 & 701471104 & 812952544 & 669841378 & 842973334 \\
\hline 2020 & 829083127 & 788854812 & 866866464 & 770221475 & 887260258 & 740038309 & 930644355 \\
\hline 2021 & 865876586 & 827982218 & 902141266 & 803533619 & 925187654 & 767524204 & 967598530 \\
\hline 2022 & 903681691 & 859442943 & 950854956 & 833339864 & 974778373 & 800430358 & 1016097404 \\
\hline 2023 & 942447762 & 901729705 & 981916419 & 879088358 & 1011907123 & 840976999 & 1061962832 \\
\hline
\end{tabular}

Figure 3: Nominal GDP Projection with 1998-2015 Data

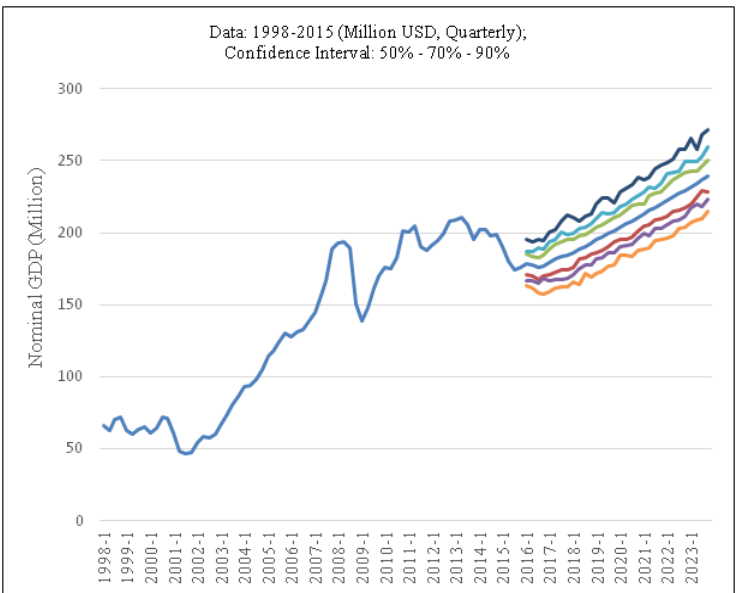


A Projection for the Turkish Economy in 2023 with a Bayesian Approach

Table 4: GDP Projection with 2002-2015 Data - USD

\begin{tabular}{|r|r|r|r|r|r|r|r|}
\hline \multirow{2}{*}{ Year } & \multirow{2}{*}{ Nom. GDP } & \multicolumn{5}{|c|}{ Confidence Interval (Thousand USD) } \\
\hline 2015 & 721051070 & \multicolumn{2}{|c|}{$50 \%$} & \multicolumn{2}{|c|}{$70 \%$} & \multicolumn{2}{c|}{$90 \%$} \\
\cline { 3 - 8 } 2016 & 728438318 & 701942363 & 752182942 & 689750070 & 768195146 & 667502612 & 793611342 \\
\hline 2017 & 756947587 & 727078666 & 784560522 & 713023262 & 802622435 & 689926856 & 829846759 \\
\hline 2018 & 785647730 & 757668315 & 816295276 & 738085477 & 832364933 & 717309822 & 850074051 \\
\hline 2019 & 818291180 & 788375418 & 845712519 & 774947268 & 866035139 & 749262163 & 895613375 \\
\hline 2020 & 850482239 & 820002538 & 879577859 & 803711740 & 896273246 & 776195324 & 927968454 \\
\hline 2021 & 882777091 & 849155780 & 915936565 & 831598994 & 936885991 & 801566996 & 963900320 \\
\hline 2022 & 914945081 & 882394941 & 948876084 & 862670724 & 966564519 & 829068777 & 998334015 \\
\hline 2023 & 947180046 & 913729768 & 982827589 & 897139306 & 1001711473 & 866082637 & 1026237387 \\
\hline
\end{tabular}

Fig.4: Nominal GDP Projection with 2002-2015 Data

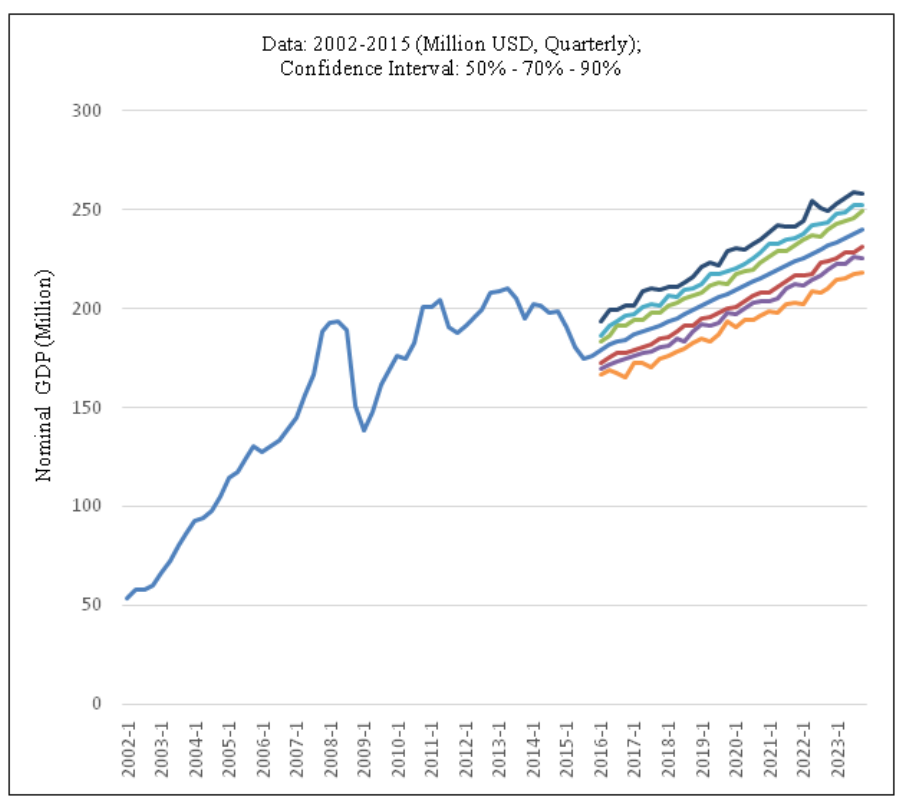

Table 5: Nominal GDP per Capita Projections with 1998-2015 Data - USD

\begin{tabular}{|l|l|l|l|l|l|l|l|}
\hline Year & $\begin{array}{l}\text { Nominal } \\
\text { GDP per } \\
\text { capita }\end{array}$ & \multicolumn{5}{|c|}{ Confidence Interval } \\
\hline 2015 & 9157,24 & \multicolumn{2}{|c|}{$50 \%$} & \multicolumn{2}{|c|}{$70 \%$} & \multicolumn{2}{c|}{$90 \%$} \\
\hline 2016 & 8977,21 & 8589,18 & 9312,81 & 8434,62 & 9531,73 & 8115,09 & 9874,47 \\
\hline 2017 & 9136,39 & 8672,95 & 9644,52 & 8388,09 & 9888,01 & 8090,73 & 10321,54 \\
\hline 2018 & 9409,85 & 9007,16 & 9849,30 & 8708,38 & 10092,36 & 8315,72 & 10465,05 \\
\hline 2019 & 9753,55 & 9326,96 & 10182,33 & 9057,73 & 10459,66 & 8602,71 & 10927,82 \\
\hline 2020 & 10101,31 & 9611,18 & 10561,65 & 9384,16 & 10810,12 & 9016,41 & 11338,70 \\
\hline 2021 & 10455,39 & 9997,82 & 10893,29 & 9702,61 & 11171,57 & 9267,80 & 11683,68 \\
\hline 2022 & 10817,34 & 10287,79 & 11382,02 & 9975,33 & 11668,39 & 9581,39 & 12162,99 \\
\hline 2023 & 11186,71 & 10703,39 & 11655,20 & 10434,64 & 12011,18 & 9982,27 & 12605,34 \\
\hline
\end{tabular}


Table 6: Nominal GDP per Capita Projection with 2002-2015 Data - USD

\begin{tabular}{|l|l|l|l|l|l|l|l|}
\hline Year & $\begin{array}{l}\text { Nominal } \\
\text { GDP per } \\
\text { capita }\end{array}$ & \multicolumn{7}{|c|}{ Confidence Interval } \\
\hline 2015 & 9157,24 & \multicolumn{2}{|c|}{$50 \%$} & \multicolumn{2}{|c|}{$70 \%$} & \multicolumn{2}{c|}{$90 \%$} \\
\hline 2016 & 9224,75 & 8889,21 & 9525,45 & 8734,81 & 9728,22 & 8453,08 & 10050,08 \\
\hline 2017 & 9489,60 & 9115,14 & 9835,77 & 8938,94 & 10062,21 & 8649,38 & 10403,51 \\
\hline 2018 & 9753,39 & 9406,04 & 10133,86 & 9162,93 & 10333,36 & 8905,01 & 10553,21 \\
\hline 2019 & 10062,41 & 9694,54 & 10399,61 & 9529,42 & 10649,51 & 9213,57 & 11013,23 \\
\hline 2020 & 10362,03 & 9990,68 & 10716,52 & 9792,19 & 10919,94 & 9456,94 & 11306,10 \\
\hline 2021 & 10659,47 & 10253,49 & 11059,87 & 10041,50 & 11312,83 & 9678,86 & 11639,02 \\
\hline 2022 & 10952,17 & 10562,53 & 11358,33 & 10326,43 & 11570,07 & 9924,20 & 11950,36 \\
\hline 2023 & 11242,88 & 10845,83 & 11666,01 & 10648,91 & 11890,16 & 10280,27 & 12181,28 \\
\hline
\end{tabular}

\section{CONCLUSION}

The projection results show that the 2023 targets of Turkey of having GDP of 2 trillion dollars and per capita GDP of 25.000 dollars are far from reaching and seem to be unattainable with the current dynamics and trends. The reasons to be far from these targets today could be explained by large depreciation of Turkish currency of lira against US dollar in 2014 and 2015. Because, by excluding 2014 and 2015 data and making projections with the data set until 2013, we have obtained the GDP of 1.5 trillion dollars and per capita GDP of 17-18 thousand dollars projections for 2023. Although they are still below the target levels, they are not very far from those targets as the figures given above.

\section{REFERENCES}

An, S., Schorfheide, F. (2007).Bayesian Analysis of DSGE Models.Econometric Reviews, 26, 113-172.

Anderson, G., Moore, G. (1985). A Linear Algebraic Procedure for Solving Linear Perfect Foresight Models.Economics Letters, 17, 247-252.

Ball, L., Robert, T. (2002).The Fed and the New Economy.American Economic Review, 92 (2), 108-114.

Clarida, R., Galí, J., Gertler, M. (1998).Monetary Policy Rules in Practice: Some International Evidence.European Economic Review, 42 (6), 1033-1067. Macroeconomic Stability: Evidence and Some Theory.Quarterly Journal of Economics, 115(1),147-180.

Clarida, R., Galí, J., Gertler, M. (2001).Optimal Monetary Policy in Open versus Closed Economies: An Integrated Approach.American Economic Review, 91 (2), 248-252.

DeJong, D. N., Ingram, B. F., Whiteman, C. H. (2000). A Bayesian approach to dynamic macroeconomics.Journal of Econometrics98(2), 203-223.

deWalque, G., Wouters, R. (2004). An open economy DSGE model linking the Euro area and the U.S. economy.Manuscript, National Bank of Belgium.

Del Negro, M., Schorfheide, F. (2004).Priors from general equilibrium models for VARs.International Economic Review45(2), 643-673. 
Del Negro, M., Schorfheide, F. (2006).How Good Is What You've Got? DSGE-

VAR as a Toolkit for Evaluating DSGE Models.Federal Reserve Bank of Atlanta Economic Review, 91, 21-37.

Del Negro, M., Schorfheide, F. (2009).Monetary Policy Analysis with Potentially Misspecified Models.American Economic Review, 99, 1415-1450.

Del Negro, M., Schorfheide, F., Smets, F., Wouters, R. (2007).On the Fit of New Keynesian Models.Journal of Business and Economic Statistics, 25(2), 123-162.

Fuhrer, J., Moore, G. (1995).Inflation persistence.Quarterly Journal of Economics $440,127-159$.

Galí, J., Monacelli, T. (2005).Monetary Policy and Exchange Rate Volatility in a Small Open Economy.Review of Economic Studies, 72, 707-734.

Ingram, B. F., Whiteman, C. M. (1994). Supplanting the Minnesota prior: forecasting macroeconomic time series using real business cycle model priors.Journal of Monetary Economics, 34(3), 497-510.

Kim, J. (2000). Constructing and estimating a realistic optimizing model of monetary policy.Journal of Monetary Economics, 45(2), 329-359.

Klein, P. (2000). Using the Generalized Schur Form to Solve a Multivariate Linear Rational Expectations Model.Journal of Economic Dynamics and Control, 24, 1405-1423.

Landon-Lane, J. (1998). Bayesian Comparison of Dynamic Macroeconomic Models.Ph.D. dissertation, University of Minnesota.

Leeper, E. M., Sims, C. A. (1994). Toward a modern macroeconomic model usable for policy analysis. In: Stanley, F., Rotemberg, J. J., eds. NBER Macroeconomics Annual 1994. Cambridge, MA: MIT Press, pp. 81-118.

Lubik, T. A., Schorfheide, F. (2007).Do Central Banks Respond to Exchange Rate Movements? A Structural Investigation.Journal of Monetary Economics, 54, 1069-1087.

Lubik, T. A., Schorfheide, F. (2006).A Bayesian look at new open economy macroeconomics. In: Mark, G., Rogoff, K., eds. NBER Macroeconomics Annual 2005. Cambridge, MA: MIT Press, pp. 313-366.

Orphanides, A. (2001). Monetary Policy Rules Based on Real-Time Data. American Economic Review, 91 (4), 964-985.

Otrok, C. (2001). On measuring the welfare cost of business cycles.Journal of Monetary Economics, 47(1), 61-92.

Rabanal, P., Tuesta, V. (2006). Euro-Dollar real exchange rate dynamics in an estimated two-country model: What is important and what is not. CEPR Discussion Paper No. 5957.

Schorfheide, F. (2000).Loss function-based evaluation of DSGE models.Journal of Applied Econometrics, 15(6), 645-670.

Sims, C. A. (1980). Macroeconomics and Reality.Econometrica, 48(4), 1-48.

Sims, C. A. (2002). Solving Linear Rational Expectations Models.Computational Economics, 20, 1-20.

Woodford, M. (2003).Interest and Prices: Foundations of a Theory of Monetary Policy. Princeton: Princeton University Press. 